\title{
Studies on the Physical Properties of Chicken Feathers
}

\author{
S. V. Bharathi ${ }^{1}$ and Indu V. Raj ${ }^{{ }^{*}}$ \\ ${ }^{1}$ Department of Veterinary Anatomy and Histology, College of Veterinary and Animal \\ Sciences, Mannuthy Thrissur-680 651, Kerala, India \\ ${ }^{2}$ Department of Veterinary Anatomy and Histology, College of Veterinary and Animal \\ Sciences, Pookode, Wayanad, Kerala, India \\ *Corresponding author
}

\section{A B S T R A C T}

\section{Keywords}

Broiler chicken, feather, physical properties

Article Info

Accepted:

15 June 2021

Available Online:

10 July 2021
Studies were undertaken on the feather of broiler chicken of six to eight weeks of age, slaughtered at Meat Technology Unit, Mannuthy. The feather samples were collected from a total of 12 birds comprising of six males and females from the broiler groups. The lengths of barbs varied depending on their location and at the base of the rachis it was longer than those at the tip. The mean length and diameter of rachis and barbs exhibited a significant difference between males and females. The mean aspect ratio of the rachis and barbs was maximum in female birds and exhibited a significant difference between groups. The barbs possessed a higher slenderness ratio/aspect ratio than the rachis. The rachis of chicken feather contributed to 53 per cent of the total weight of a feather while the barbs contributed to 47 per cent. Thus chicken feathers possessed approximately half feather barbs and half rachis by weight in the present study and showed no significant difference between male and female birds under study. The density of whole chicken feathers measured in the present study exhibited no significant difference between sexes. The moisture content of the chicken feather fractions varied between eight and eleven percent. The moisture content of the barbs was the highest, followed by that for whole feathers and rachis. The moisture regain values followed the same trend as the moisture content of the feather fractions and exhibited no significant difference between sexes.

\section{Introduction}

Poultry industry has taken a quantum leap in the last three decades and now India is the fifth largest poultry producer in the world. Chicken meat has always been the favourite and dominated the global poultry industry. This also generates millions of tonnes of waste which if not properly disposed, becomes one of the major environmental pollutants. The structure and properties of chicken feathers are very distinct when compared to any other natural or synthetic fibre. The barbs of poultry feathers have unique properties which can be utilized for making composites and textiles. Keratin fibres from chicken feathers, is a rich 
source of high performance material and research on use of this keratin in the field of tissue engineering, water purification, textile finishing and in plastics is in progress.

Hence it is essential to find alternate ways to utilize the feather wastes from poultry industry to make the poultry industry more profitable. The present study was conducted to assess the physical properties of feather in broiler chicken. It will be contributory to the existing knowledge and will also form a basis for future research on techniques for processing chicken feather to realize its full potential.

\section{Materials and Methods}

Studies were undertaken on the feather of broiler chicken of six to eight weeks of age, slaughtered at Meat Technology Unit, Mannuthy. The feather samples were collected from a total of 12 birds comprising of six males and females from the broiler groups.

Immediately following exsanguination, primary and secondary remiges were collected from the 12 wing feathers of each bird to study the physical properties.

To clear out the foreign materials clung to the feathers, they were first washed with five per cent non-ionic liquid soap solution followed by rinsing and exposed to natural light until completely dried. The feathers were sterilized with $95 \%$ ethanol at $21^{\circ} \mathrm{C}$ for $30 \mathrm{~min}$ (Fan, 2008). They were then rinsed with water and dried. The sterilized feathers were then processed to get fibres.

The feathers were dried and conditioned at a relative of humidity $(\mathrm{RH}) 65 \pm 2 \%$ and a temperature of $20 \pm 2{ }^{\circ} \mathrm{C}$. The barbs were separated from the rachis manually by cutting with scissors. The samples of chicken feathers were then tested to characterize their physical properties.

\section{Length}

The length of the feather barbs was determined by single fibre measurement method given by Booth (1974). Fibre length was measured manually with the help of a scale and a pair of forceps by applying tension just to straighten the fibres. The average length of feather and feather fractions were calculated.

\section{Diameter}

The diameter of the feather fractions (rachis and barbs) were measured at three different points along each fraction using stereozoom microscope. The average diameter of each feather fraction was calculated.

\section{Aspect Ratio}

The aspect ratio was calculated by calculating the ratio between average length and average width of the feather fractions (Jagdeeshgouda et al., 2014).

Aspect ratio/ Slenderness ratio $=$ Length of the sample/ Width of the sample

\section{Fineness}

Fineness of textile fibre is expressed in terms of denier which is the weight in grams of 9000 $\mathrm{m}$ of the material. Fineness of barbs was determined by weighing a known length of the barb as per Reddy and Yang (2007).

\section{Density}

Samples were prepared by grinding feather in a pulverizer. Feather pellets were then formed by pressing known mass of powdered feather under pressure using a $\mathrm{KBr}$ presser. The diameter and height of the pellet was measured immediately after pressing. The density of chicken feather was measured by 
displacing a known volume and weight of ethanol with an equivalent amount of fibre (Jagdeeshgouda et al., 2014).

Density $=$ Mass $(\mathrm{m}) /$ volume $(\mathrm{V})$

\section{Moisture Content}

Whole chicken feather and the feather fractions (rachis and barbs) were first dried in a hot air oven at $105^{\circ} \mathrm{C}$ for $4 \mathrm{~h}$. Two-gram samples were processed according to ASTM D1576-90 using the formula (ASTM, 2001):

Moisture content $=\mathrm{W} 1-\mathrm{W} 2 / \mathrm{W} 1 * 100$

$\mathrm{W} 1$ = Original mass of sample $(\mathrm{g})$, and

$\mathrm{W} 2=$ Oven dry mass of sample $(\mathrm{g})$.

\section{Moisture Regain}

The oven dried feather samples as prepared for measuring moisture content were allowed to regain moisture under the standard testing conditions of $21^{\circ} \mathrm{C}$ and 65 per cent relative humidity (RH). The ratio of the dry weight of the samples to the conditioned weight was taken as the percentage moisture regain (Das et al., 2017).

The data were analyzed statistically (Snedecor and Cochran, 1994).

\section{Results and Discussion}

\section{Gross Structure of Feathers}

The remiges or wing feathers were mainly composed of three distinct units viz., rachis (primary structure), barbs (secondary structures) and barbules (tertiary structures). The main shaft comprised of rachis and calamus which was seen along the entire length of the feather. It was four sided, solid, tapering and formed the central stiff cylindrical portion of the contour feather. The calamus or quill (lower shaft) was found to be rounded, transparent, hollow and devoid of vane structure in all the birds under study. The interlocking feather vane comprised of barbs that branched from the rachis and barbules that branched from barbs in all the birds. Neighbouring barbules adhered to one another via hook-and-groove structures to form an organized feather vane. These results are parallel with the observations of Tesfaye et al., (2017) and Reddy and Yang (2007) in chicken. The rachis was thick and stiff and unsuitable as a natural protein fibre but the length, strength and flexibility of feather barbs made them suitable as natural protein fibres.

\section{Length}

The mean length of the rachis of broiler male and female were $11.73 \pm 0.15 \mathrm{~cm}$, and $11.12 \pm 0.79 \mathrm{~cm}$ respectively. This is in agreement to the measurements of rachis; 7 inches (Reddy and Yang, 2007); 40 to 120 $\mathrm{mm}$ (Zhan and Wool, 2011) and 40 to $150 \mathrm{~mm}$ (Tesfaye et al., 2017). The mean length of the barbs of broiler male and female were $1.17 \pm 0.21 \mathrm{~cm}$ and $1.05 \pm 0.22 \mathrm{~cm}$ respectively. The mean length of rachis and barbs exhibited a significant difference $(\mathrm{p}<0.01)$ between males and females. Quite similar observations were made in chicken feather as 1 to $4.5 \mathrm{~cm}$ (Reddy and Yang, 2007) (Jagadeshgouda et al., 2014 and 1 to $45 \mathrm{~mm}$ (Pasayev et al., 2017). Purslow and Vincent (1978) opined that very short barbs could be chosen to spun into thread for weaving cloth and after mixing with other synthetic materials to prepare mats. According to May (2002) the fibres having length greater than $12.7 \mathrm{~mm}$ could be spun and therefore chicken feather rachis and barbs were suitable for this purpose. Reddy and Yang (2007) noticed that the length of barbs were similar to cotton fibres and therefore suitable for processing on textile machines like natural fibres. 


\section{Diameter}

The mean diameter of rachis measured $12.67 \pm 0.21 \mathrm{~mm}$ and $11.83 \pm 0.17 \mathrm{~mm}$ in broiler male and female respectively similar to the observations of Martinez-Hernandez et al., (2005) in chicken. The mean diameter of the barbs of broiler male and female were $28.50 \pm 0.96 \mu \mathrm{m} \quad$ and $\quad 26.00 \pm 0.37 \mu \mathrm{m}$ respectively. The diameter of rachis and barbs exhibited a significant difference $(\mathrm{p}<0.01)$ between males and females. The chicken feather barb diameter measurements made earlier varied between 15 to $110 \mu \mathrm{m}$ (Huda and Yang, 2009). The barbs had a spinnable diameter range which made it suitable for textile application (Hearle and Morton, 2008). Tesfaye et al., (2017) reported that since feather fibres were finer in diameter than wood pulp, it could be used to make paper products such as filter papers and decorative papers which were made from wood pulp.

\section{Aspect Ratio}

The mean aspect ratio of the rachis of broiler male and female were $87.28 \pm 1.33$ and $87.54 \pm 1.81$ respectively. Jagadeeshgouda et al., (2014) noticed that the average aspect ratio for rachis was 40.77 . The slight variation seen in the present study might be because the length and diameter of feather fibre was different in different locations. Slenderness ratio/aspect ratio was related to the length and breadth of fibres (Tesfaye et al., 2017).

The mean aspect ratio of the barbs of broiler male and female were $346.67 \pm 4.01$ and $336.33 \pm 2.19$ respectively. The barbs possessed a higher slenderness ratio/aspect ratio than the rachis in both broiler and layer chicken. These measurements are similar to the observations of Shah and Yang (2009) and Adetola et al., (2014) in chicken. Schmidt (1998) and Tesfaye et al., (2017) reported that the poultry feather barb had an aspect ratio more than that of its rachis and was more durable. The desired aspect ratio of the fibre to be used in the textile manufacturing was between 200 and 600 (Fathima and Balasubramanian, 2006). The results of the present study suggested that the chicken feather barbs of both broiler and layer birds were suitable for use as fibres in textile industries whereas rachis was inappropriate for such applications.

\section{Fineness}

In the present study the mean fineness of the barbs of broiler male and female were $84.17 \pm 2.39$ and $81.67 \pm 2.47$ respectively similar to the reports of Reddy and Yang (2007) in chicken suggesting that chicken feather barbs were suitable for processing as natural fibres. The reports of Neha et al., (2015) that the fineness of chicken feather fibre was 36.48 denier is lower than that seen in the present study. The slight dissimilarity seen might be due to the difference in processing conditions and form of the feather fibre under study.

\section{Mass of Chicken Feather Fractions}

The chicken feather rachis and barb per cent showed no significant difference $(\mathrm{p}<0.01)$ between between males and females. The rachis of chicken feather contributed to 53 per cent of the total weight of a feather while the barbs contributed to 47 per cent in broiler chicken. Thus broiler chicken feathers possessed approximately half feather barbs and half rachis by weight as reported by Martinez-Hernandez et al., (2005) in chicken.

\section{Density}

The mean density of the barbs of broiler male and female were $0.6667 \pm 0.00$ and $0.6750 \pm 0.00 \mathrm{~g} / \mathrm{cm}^{3}$ respectively and exhibited no significant difference between sexes. These 
observations are in agreement with the reports of Barone and Schmidt (2005) in chicken feathers. According to them the density of chicken feather was lower than cellulose fibres and wool. Reddy and Yang (2007) suggested that the reason for the light weight and low density of the rachis and barbs of chicken feather might be due to their peculiar inner honeycomb structure. According to Saravanan and Dhurai (2012) and Chinta et al., (2013), density of chicken feathers were lower than all the commercially available natural or synthetic fibres today. Tesfaye et al., (2017) opined that incorporation of chicken feather fractions would result in production of lightweight composites that would tremendously reduce the transportation and construction costs.

\section{Moisture Content}

In the present study the moisture content of the chicken feather fractions varied between eight and eleven percent. The moisture content of the barbs in broiler chicken was 11 per cent, followed by that for whole feathers at 9.5 per cent and rachis at 8.5 per cent. Similar observations were made by Chinta et al., (2003), in chicken feathers, barbs and rachis.

According to Munawar et al., (2007) and Jones et al., (1998) high moisture content of the raw materials used might bring about microbial growths and thus rapid deterioration of the product. This would deter the processing or bonding in the final products.

Further high moisture content would also increase the weight and hence transportation costs of the products. However, in the present study in all the groups of birds the average moisture content of the chicken feathers did not exceed 11 per cent suggesting that the material could be safely stored for long time periods without damage due to growth of microbes.

\section{Moisture Regain}

The moisture regain values of the feather fractions also followed the same pattern as its moisture content in the present study. In broiler chicken the moisture regain in barbs was the highest (12 per cent), followed by that for whole feathers (10.5 per cent) and rachis (9.5 per cent). These results are parallel with the results of Reddy and Yang (2007) and Tesfaye et al., (2017) in chicken feather fractions.

The comfort of textile fabrics depended on its moisture content and fibres having good moisture regain absorbed water-born dyes and finishes applied on it more easily (Freddi et $a l ., 2003)$. Reddy and Yang (2007) found that the moisture regain values of the feather fractions of chicken were higher than that of cellulose fibres such as cotton but lower than that of wool.

Clothes made from fibres with more moisture regain were easy to process and comfortable to wear suggesting that products made from chicken feather barbs would provide better comfort than that those made from cotton. According to Tesfaye et al., (2017) chicken feather fractions used for several types of applications that required liquid retention. For example, in the medical industry, drugs could be inserted into these microfibrous materials for release in the body by means of body temperature.

The physical properties of feather like length, diameter, aspect ratio of the rachis and barbs, feather weight and density, and mean fineness of feather fractions make it suitable for use as a raw material in bioplastics, textile sizing, enzyme production, pharmaceuticals and cosmetics industry. Future research work may be carried out for extraction of valuable materials from poultry feathers, and its conversion into relevant high-value products. 
This would bring in new industries and job opportunities and make the poultry industry more competitive.

\section{References}

Adetola, S. O., Yekini, A. A. and Olayiwola, B. S. 2014. Investigation into Physical and Mechanical Properties of Few Selected Chicken Feathers Commonly Found in Nigeria. IOSR J. Mechanical Civil Engng. 11: 45-50.

ASTM D1576-90, 2001. Standard Test Method for Moisture in Wool by Ovendrying [standard on-line] ASTM International, West Conshohocken, Pennsylvania, United States.

Barone, J. R. and Schmidt, W. F., 2005. Polyethylene reinforced with keratin fibres obtained from chicken feathers. Composites Sci. Technol. 65: 173-181.

Booth, J. E. 1974. Principles of Textile Testing. ( $3^{\text {rd }}$ Ed.). Newness Butter Worth, London, 321p.

Chinta, S., Landage, S. and Yadav, K. 2013. Application of chicken feathers in technical textiles. Int. J. Innovative Res. Sci. Engng Technol. 2: 11581165.

Das, S., Jose, S. and Pandit, P. 2017. Physical properties characterization of Natural Protein Fibre Peacock Feather Barbs. bioRxiv. 1: 238626.

Fathima, M. and Balasubramanian, A. 2006. Effect of plant growth regulators on the quality of bast fibres in Abelmoschus esculentus (Linn.) Moench. Acta Bot. Croatica. 65: 101112.

Freddi, G., Innocenti, R., Arai, T., Shiozaki, H. and Tsukada, M. 2003. Physical properties of wool fibres modified with isocyanate compounds. J. Appl. Polym. Sci. 89: 1390-1396.

Hearle, J. W. and Morton, W. E.
2008. Physical Properties of Textile Fibres. (4 ${ }^{\text {th }}$ Ed.). Elsevier, United Kingdom, 796p.

Huda, S. and Yang, Y. 2009. Feather fibre reinforced light-weight composites with good acoustic properties. $J$. Polym. Environ. 17: 131.

Jagadeeshgouda, K. B., Reddy, P. R. and Ishwaraprasad, K. 2014. Experimental study of behaviour of poultry feather fibre: a reinforcing material for composites. Int. J. Res. Engng. Technol. 3: 362-366.

Jones, L. N., Riven, D. E. and Tucker, D. J. 1998. Handbook of Fibre Chemistry. $\left(2^{\text {rd }}\right.$ Ed.). Marcel Dekker, Inc., New York, 1083p.

Martinez-Hernandez, A. L., Velasco-Santos, C., De Icaza, M. and Castano, V. M. 2005. Microstructural characterisation of keratin fibres from chicken feathers. Int. J. Environ. Pollut. 23: 162-178.

May, O. L. 2002. Quality improvement of upland cotton (Gossypium hirsutum L.). J. Crop Prod. 5: 371-394.

Munawar, S. S., Umemura, K. and Kawai, S. 2007. Characterization of the morphological, physical, and mechanical properties of seven non wood plant fibre bundles. J. Wood Sci. 53: 108-113.

Neha, S., Alka, G. and Omre, P. K. 2015. Characterization of chicken feather fibre as novel protein fibre for commercial applications. Int. J. Trop. Agric. 33: 3373-3377.

Paşayev, N., Kocatepe, S., Maraş, N., Soylak, M. and Erol, M. 2017. Investigation some characteristics of chicken feather's rachis. IOP Conference Series: Materials Science and Engineering; October, 2017, Kayseri, Turkey. pp. 192013.

Purslow, P. P. and Vincent, J. F. V. 1978. Mechanical properties of primary 
feathers from the pigeon. $J$. Exp. Biol. 72: 251-260.

Reddy, N. and Yang, Y. 2007. Structure and properties of chicken feather barbs as natural protein fibres. J. Polym. Environ. 15: 81-87.

Saravanan, K. and Dhurai, B. 2012. Exploration on the amino acid content and morphological structure in chicken feather fibre.J. Textile Apparel Technol. Mgmt. 7: 1-6

Schmidt, W. F. 1998. Innovative feather utilization strategies. Proceedings of the 1998 National poultry waste management symposium; $19^{\text {th }}$ to $22^{\text {nd }}$ October, 1998, Springdale, Arkansas, Auburn, United States. pp. 276-282.

Shah, H. and Yang, Y. 2009. Feather fibre reinforced light-weight composites with good acoustic properties. $J$.
Polym. Environ. 17: 131-142.

Snedecor, G. W. and Cochran, W. G. 1994. Statistical Methods. $\left(7^{\text {th }}\right.$ Ed.). The Iowa State University Press, USA, $313 p$

Tesfaye, T., Sithole, B., Ramjugernath, D. and Chunilall, V. 2017. Valorisation of chicken feathers: Characterisation of physical properties and morphological structure. J. Cleaner Prod. 149: 349365.

Zhan, M. and Wool R. P. 2011. Mechanical properties of chicken feather fibres. Polym. Composites. 32: 937-944.

Zhang, Y., Zhao, W. and Yang, R. 2015. Steam Flash Explosion Assisted Dissolution of Keratin from Feathers. ACS Sustain. Chem. Engng. 3: 20362042.

\section{How to cite this article:}

Bharathi, S. V. and Indu V. Raj. 2021. Studies on the Physical Properties of Chicken Feathers. Int.J.Curr.Microbiol.App.Sci. 10(07): 309-315. doi: https://doi.org/10.20546/ijcmas.2021.1007.033 